\title{
Multi-layer Partition Method Combined with Multi-target Genetic Optimization for Urban Power Grid Structure Planning
}

\author{
Z.Q. YAO ${ }^{1}$ \& C.W. ZHAO ${ }^{1}$ \& Y.C. ZONG ${ }^{1}$ \\ F.J. $\mathrm{CHI}^{2} \&$ J. ZHANG ${ }^{2}$ \\ L.Y. LIU ${ }^{3}$
}

\author{
${ }^{1}$ The east city power supply subsidiary company of Tianjin, State Grid, 300250, China; \\ ${ }^{2}$ State Grid Tianjin Electric Power Company, Tianjin, 300010, China; \\ ${ }^{3}$ Key Laboratory of Smart Grid of Ministry of Education, Tianjin University, Tianjin 300072, China
}

KEYWORD: power grid planning, partition method, the multi-target genetic optimization method, grid structure

ABSTRACT: The planning and designing of the power grid structure is most important in the planning and construction of power grid. With the development of urbanization and widespread insertion of distributed generations, the traditional planning method for urban power grid structure is facing new challenges and uncertainties. A multi-layer partition method combined with the multi-target genetic optimization is proposed in this paper. First, the definition and the mathematic model of the proposed method are introduced. Second, its specific implementation scheme and technological process are presented in detail. Finally, a numerical example is given to testify its feasibility. This method considers the power supply ability as its objective function, so it can ensure its optimization result have higher power supply reliability than other traditional planning method.

\section{Introduction}

With the development of urbanization of China, many new towns and cities have been built during these years, which require more stable energy supply. Also, as the increasing pressure on the environment protection and resource consumption, more and more renewable energy, together with electric vehicle charge station, are joined into the power system, as a major way to solve these challenges. These will surely bring new uncertainties to the power grids. In the future, smart grid is aimed to provide secure, reliable, clean and high quality power supply, which requires the new planning, the reorganization and the construction of local power grid in order to achieve this target [1][2][3][4].

In recent years, as the development of power grid designing and planning technique, some new planning concepts have emerged: 1) the planning idea has changed from guaranteeing basic power supply into the idea that lower level grids should support the higher level grids sufficiently, which emphasizes the system's security and the reliability for the power supply to the customers in the gird's terminal. 2) the idea that emphasizes the optimization of economic profits of enterprises has emerged. Meanwhile, the balance between economic risk of building new grids or rebuilding exist grids, and the customers' economy, reliability and security risk, needs to be considered carefully. 3) the appearing of distributed generation (DG): DG's appearing will surely have a large impact on the temporary centralized power supply mode [5].

Aiming at those new situations and new rising problems in the field of power grid's planning and designing, many scholars have raised many methods, models and algorithm, trying to solve those problems, such as Pareto multi-target optimization method [6], hierarchy multi-target programming 
[7], fuzzy programming method [8][9], and so on; as for solution algorithm, there have been heuristic algorithm; "step by step adding lines" method together with "step by step subtract lines" method, based on sensitivity optimization algorithm [10]. There also have been mathematical programming method [11] and other algorithm, which enriches the solving methods for the grid's planning and construction.

Based on predecessors' work, the united planning method, combining the consideration of power gird's net rack structure and multi-layer partition method, is discussed in this paper, and multi-target genetic algorithm is applied to conduct this method.THE MULTI-LAYER PARTITION METHOD COMBINED WITH MULTI-TARGET GENETIC OPTIMIZATION

There are major 3 indications to be considered as the target function of a optimization for the power gird: 1) economy: get the maximum economy revenue through minimum invest; 2) reliability: this can be quantified as Lost $_{\min }$ (minimum load shedding); 3) power supply sufficiency, which can be quantified as PSA (power supply ability) and is used to evaluate the ability of power supply under normal operation of the system.

The planning method in this paper adopts power supply ability as the objective function for the planning purpose.

\section{Partition method}

In China, according to paper [12], nowadays the partition method for the urban power grid system is as follows:

A maximum voltage level substation $(500 \mathrm{kv})$ is the central point in a partition district. Those lower voltage level substations $(220 \mathrm{kv}, 110 \mathrm{kv})$ in this district will be put under it. After partition, there will be one maximum voltage level substation together with several lower voltage level substations. In order to boost the efficiency of partition, the specific procedure of partition is as follows:

When facing a specific $220 \mathrm{kv}$ substation, we need to identify its "partition attribute value" (PAV) [13]. According to different connection types with $500 \mathrm{kv}$ substation for a $220 \mathrm{kv}$ substation, there will be 4 situations:

1) if the $220 \mathrm{kv}$ substation is connected to only one $500 \mathrm{kv}$ substation, then the node number of this $500 \mathrm{kv}$ substation will be its partition attribute value. 2) if a $220 \mathrm{kv}$ substation is connected to several $500 \mathrm{kv}$ substations, then those 500kv substations' node number will be its PAV together. 3) if a $220 \mathrm{kv}$ substation (A) is connected to another $220 \mathrm{kv}$ substation (B), then B's PAV will be A's. 4) if a $220 \mathrm{kv}$ substation is put under a $500 \mathrm{kv}$ substation's command according to the planning and designing prospectus, then its PAV will be the 500kv substation's node number.

\section{Power supply ability assessment for urban power system based on linear programming}

In this part, linear programming method [14] will be adopted to build maximum power supply evaluation model for urban power system. Its objective function is to maximize the sum of active load of all load point in the grid. Meanwhile, equality constraints for net power balance are direct current equations; inequality constraints are the proper value ranges (top and bottom limitation) for lines' active power; power constraints need to be met in generation nodes and load nodes.

From above here are linear programming mathematical expression:

$$
\begin{gathered}
P S C=\max \sum_{i=1}^{m_{\text {load }}} p_{i} \\
\text { s.t. } P=B \theta \\
\text { s.t: } C_{L, \text { low }} \leq\left|C_{L}\right| \leq C_{L, \text { high }}, \quad p_{i, \text { low }} \leq\left|p_{i}\right| \leq p_{i, \text { high }}
\end{gathered}
$$


in the expression, $m_{\text {load }}$ is the number of load nodes; $p_{i}$ is the active power of load $i ; P, \theta$ are node's active load input and its voltage phase angel, $B$ is network admittance matrix; $C_{L, \text { low }}, C_{L, h i g h}$ are bottom and top limitation of line capacity; $p_{i, l o w}, p_{i, h i g h}$ are bottom and top limitation of node's active power.

By adopting direct current as constraints for optimization, although measure will reduce the computational accuracy, it will significantly improve the calculation speed for optimization process. If we take alternation current into consideration, the accuracy will be improved limitedly, but the time of calculation will have a fold increase, which is unnecessary for power grid planning situation where lots of planning schemes need to be compared efficiently.

\section{Two layers, multi-target united planning model}

Based on the partitioned and layered power system, the two layers, multi-target united planning model will be built.

The first layer is the planning for overall net rack. In order to insure the overall optimization direction and take into consideration the necessity of mutual support among urban power system's different partition zones, the overall power supply ability can be added to objective functions. In this layer, as the whole net rack will not be fully-operation, the reliability won't be considered in the optimal process.

The second layer is for the optimization of partitioned mode planning: as the investment has been considered in $1^{\text {st }}$ layer, it will not be reconsidered in this layer; the objective functions include the sum of every partition zone's power supply ability (PSA) and the sum of power insufficiency expectation.

The mathematic model for $1^{\text {st }}$ layer planning is :

$$
\begin{aligned}
& L 1: \operatorname{Min}\left[C_{f}(x),-P_{s c}(x, y)\right] \\
& \text { s.t.g }(x, y)\{\leq,=, \geq\} 0
\end{aligned}
$$

In the expression, $y$ is continuous variable, such as current, voltage; $x$ is integer variable, indicating decision variables for line construction; $C_{f}(x)$ indicates line investment; $P_{s c}(x, y)$ is the power supply ability of connected net frame; $g(x, y)\{\leq,=, \geq\} 0$ is the gather of technical constraints in planning, such as grid structure constraints, direct current constraints, N-1 condition current constraints.

The mathematic model for $2^{\text {nd }}$ layer planning is:

$$
\begin{aligned}
& L 2: \operatorname{Min}\left[-\sum_{i=1}^{m_{\text {partition }}} P_{S C l_{i}}(x, y), \sum_{i=1}^{m_{\text {partition }}} L_{i}(x, y)\right] \\
& \text { s.t } g_{i}(x, y)\{\leq,=, \geq\} 0, d_{i}(x, y)\{\leq,=, \geq\} 0 \\
& i=1,2, \ldots m_{\text {partition }}
\end{aligned}
$$

In the expression, $y, x$ mean the same as the $1^{\text {st }}$ layer; $m_{\text {partition }}$ indicates the number of partitioned zone; $P_{S C l_{i}}(x, y)$ is the power supply ability of zone $i ; g_{i}(x, y)\{\leq,=, \geq\} 0$ is the technical 
constraints of zone $i ; d_{i}(x, y)\{\leq,=, \geq\} 0$ is the feasible constraints of zone $i$, including the situation where the substation capacity is smaller than the generation power in a certain partitioned zone.

\section{The transform and analysis of two-layer, multi-target planning}

From the discussion above, the two-layer, multi-target optimization planning model has been built. However, as this kind of model is quite complicated and difficult to solve, it need to be transformed [15].

Considering this optimization's characters, here we choose two-layer, multi-target minimization planning as the result of transform of the two-layer, multi-target optimization planning model mentioned above. Its general type can be:

$$
\begin{aligned}
& \min _{(x) \in Z}\left[P_{1} F_{1}(x), P_{2} F_{2}(x)\right] \\
& F_{1}(x)=\left(f_{1}^{1}(x), f_{2}^{1}(x), \ldots f_{l 1}^{1}(x)\right), \\
& F_{2}(x)=\left(f_{1}^{2}(x), f_{2}^{2}(x), \ldots f_{l 2}^{2}(x)\right)
\end{aligned}
$$

In the expression, $F_{1}(x) \quad F_{2}(x)$ indicate $1^{\text {st }}$ and $2^{\text {nd }}$ layer's objective function respectively; $\mathrm{x}$ indicates the variable which belongs to each layer and has its own impact on each layer's objective function. $\mathrm{Z}$ indicates the feasible region of this two-layer, multi-target minimization planning.

\section{Multi-target genetic optimization}

Faced with this two-layer, multi-target minimization planning problem, genetic optimization is adopted. Its specific process is as follows: 


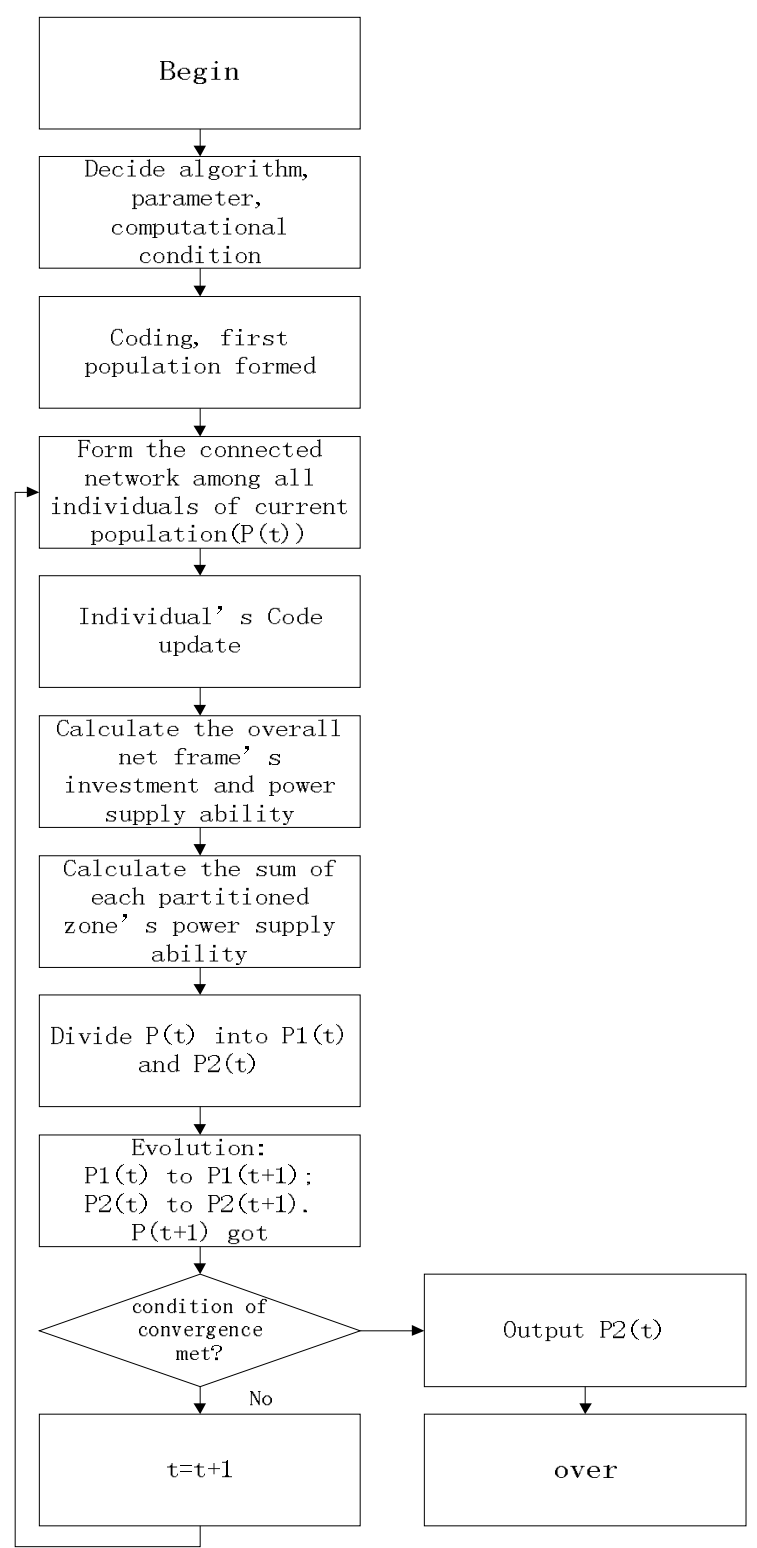

Fig 1 two-layer,multi-target genetic optimization flow

\section{Numerical example}

Fig 2 shows the initial power network frame. After using united planning method combining multi-layer partition and multi-target genetic optimization, we can get the re-planning power network frame presented in Fig 3.

In the Fig, those circles mean load nodes; the red lines mean the newly built lines; the dotted lines indicate those spare line. 


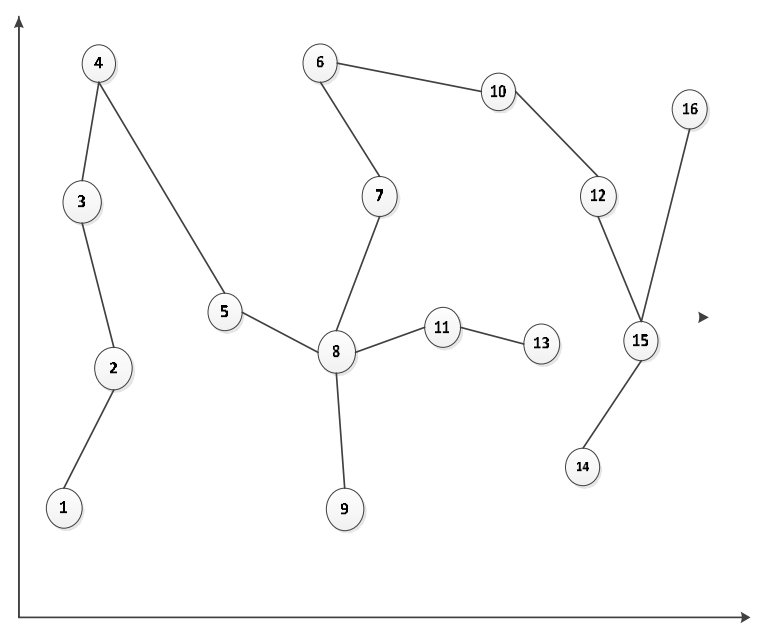

Fig 2 initial power network frame

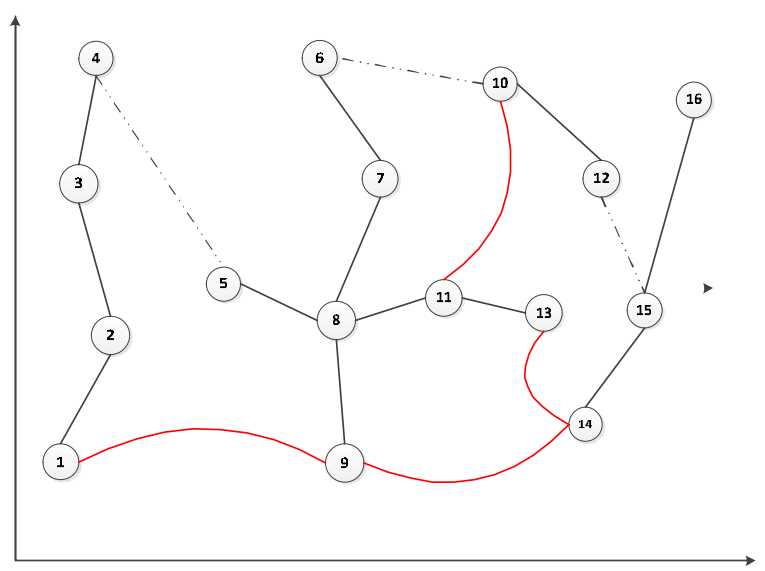

Fig 3 re-planed power network frame

\begin{tabular}{|l|c|l|c|}
\hline Load node & The line can be built & Load node & The line can be built \\
\hline 1 & To 2、9 & 9 & To 1、2、8 \\
\hline 2 & To 1、3、5、9 & 10 & To 6、12 \\
\hline 3 & To 2、4、5 & 11 & To 8、13 \\
\hline 4 & To 3、5、6 & 12 & To 10、15、16 \\
\hline 5 & To 4、8 & 13 & To 11 15、12、14 \\
\hline 6 & To 7、10 & 14 & To 13、15 \\
\hline 7 & To 6、8、11 & 15 & To 12、13、14、16 \\
\hline 8 & To 5、7、9、11 & 16 & To 12、15 \\
\hline
\end{tabular}

Table 1 feasible construction lines

By using the united planning mentioned above, we can re-optimize the current power grid network. The results are showed in Form 1. Lines from load nodes 1 to 9, 9 to 10,13 to 14, 10 to 11 (red lines) are suggested to be built after optimization, in order to maximize the overall network's power supply ability; meanwhile, the original lines 1-2-3-4, 5-8-11-13, 6-7-8-9, 14-15-16 can be used 
continuously; and the original lines 4 to 5,6 to 10 and 12 to 15 (dotted lines) can be the spare lines in case of fault and outage and they will be in open-loop operation in normal situation.

\section{CONCLUSION}

A united planning method for urban power grid combining multi-layer partition and multi-target genetic optimization, has been presented in this paper. This planning method considers power supply ability as its main objective function in order to optimize the whole grid's power supply sufficiency.

The two-layer, multi-target planning model has been built to conduct the united planning method. After converting this model to a minimization planning model, genetic optimization method is adopted to solve this optimization problem. The feasibility and accuracy of this united planning method is testified in a calculation example.

\section{REFERENCES}

[1]. Lukovic S, Kaitovic I, Mura M, et al. Virtual Power Plant As a Bridge between Distributed Energy Resources and Smart Grid[C]// System Sciences (HICSS), 2010 43rd Hawaii International Conference on. IEEE, 2010:1-8.

[2]. O'Neill R. Smart grids sound transmission investments [In my View][J]. Power \& Energy Magazine IEEE, 2007, 5(5):104 - 102.

[3]. Bayram I S, Michailidis G, Devetsikiotis M, et al. Smart Vehicles in the Smart Grid: Challenges, Trends, and Application to the Design of Charging Stations[M]// Control and Optimization Methods for Electric Smart Grids. Springer New York, 2012:133-145.

[4]. Ipakchi A, Albuyeh F. Grid of the future[J]. IEEE Power \& Energy Magazine, 2009, 7(2):52 62.

[5]. Chowdhury A A, Koval D O. Value-based distribution system reliability planning[J]. IEEE Transactions on Industry Applications,1998,34(1):23-29.

[6]. Yang Y, Wu J F, Zhu X B, et al. A Hybrid Evolutionary Algorithm For Finding Pareto Optimal Set In Multi-Objective Optimization[C]// Natural Computation (ICNC), 2011 Seventh International Conference on. 2011:1233-1236.

[7]. Ji R, Xie X, Yao H, et al. Vocabulary hierarchy optimization for effective and transferable retrieval[C]// 2013 IEEE Conference on Computer Vision and Pattern Recognition. IEEE, 2009:1161-1168.

[8]. Biswas A, Kumar De A. A priority based fuzzy programming approach for multi-objective probabilistic linear fractional programming[C]// IEEE International Conference on Fuzzy Systems. 2013:1 - 6 .

[9]. Ramirez-Rosado I J, Dominguez-Navarro J A. Possibilistic model based on fuzzy sets for the multi-objective optimal planning of electric power distribution networks[J]. IEEE Transactions on Power Systems,2004,19(4):1801-1810.

[10]. Dymond A S, Kok S, Heyns P S. The sensitivity of multi-objective optimization algorithm performance to objective function evaluation budgets[C]// Evolutionary Computation (CEC), 2013 IEEE Congress on. IEEE, 2013:1868 - 1875.

[11].Hindi K S, Brameller A. Design of low-voltage distribution networks: a mathematical programming method[J]. Proceedings of the Institution of Electrical Engineers, 1977, 
124(1):54 - 58.

[12]. Guan B B, Wang Y, Ming-Feng W U. Discussion on Smart Grid Technologies[J]. Shanxi Electric Power, 2014.

[13]. Aoki K,Nara K,Satoh T,et al. New approximate optimization method for distribution system planning[J]. IEEE Transactions on Power Systems, 1990,5(1):126-132.

[14].Tang $Y$.Power distribution system planning with reliability modeling and optimization[J].IEEE Transactions on Power System,1996,11(1):181-189.

[15].Nara K,Satoh T,Kuwabara H,et al. Distribution systems expansion planning by multi-stage branch exchange[J]. IEEE Transactions on Power Systems, 1992,7(1):208-214. 